\begin{tabular}{|c|l|}
\hline Title & $\begin{array}{l}\text { A Study on the Structure of Pyridine Extracts from Coals by High Resolution Nuclear Magnetic Resonance } \\
\text { Spectroscopy }\end{array}$ \\
\hline Author(s) & Takeya, Gen; Itoh, Mitsuomi; Suzuki, A kira; Y okoyama, Susumu \\
\hline Citation & Memoirs of the Faculty of Engineering, Hokkaido University, 11(6), 613-628 \\
\hline Issue Date & 1965-08 \\
\hline Doc URL & http:/hdl.handle.net/2115/37844 \\
\hline Type & bulletin (article) \\
\hline File Information & 11(6)_613-628.pdf \\
\hline
\end{tabular}

Instructions for use 


\title{
A Study on the Structure of Pyridine Extracts from Coals by High Resolution Nuclear Magnetic Resonance Spectroscopy
}

\author{
Gen TAKEYA, Mitsuomi ITOH, \\ Akira SUzUKI and Susumu YOKOYAMA
}

\section{Contents}

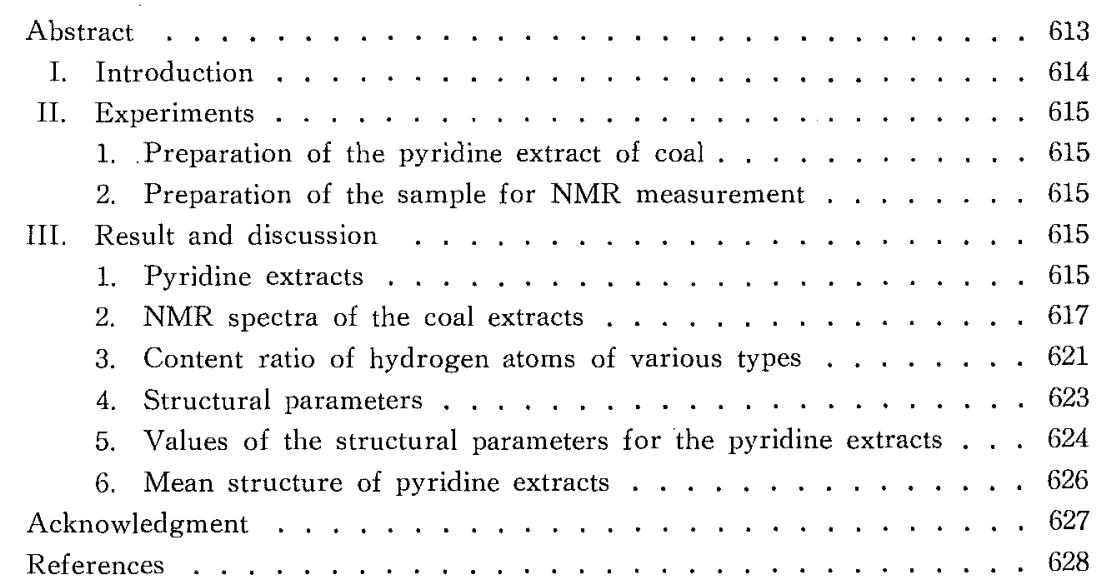

\begin{abstract}
In this paper, a study on the structural analysis of pyridine extracts of 12 Japanese coals of various carbon contents ranging from 60.9 to 85.6 per cent was made by a high resolution nuclear magnetic resonance $(60 \mathrm{Mc}) \mathrm{spec}$ troscopy. The 12 coals include 1 peat and 1 lignite samples.

The sample materials were made by Soxhlet extraction of coals with pyridine, and the free-from-solvent dried samples were redissolved in deuteropyridine resulting in a solution containing approximately 10 per cent of coal extract by weight for NMR spectroscopy.

Intensities of peaks assigned to three sorts of hydrogen in the constitution of the extracts, i.e. hydrogens in aromatic rings, bonded to carbon atoms in $\alpha$-position to aromatic rings and others with the exception of hydrogens of the hydroxyl groups-were integrated in the ranges of respective location on the magnetic field and were expressed as $H_{a}, H_{\alpha}$ and $H_{0}$. The signals of
\end{abstract}


hydrogen in hydroxyl groups failed to appear in the NMR spectra. At the same time, the contents of constitutive carbon atoms, hydrogen and oxygen atoms contained in the various functional groups, were measured by elementary analyses and chemical analyses. From these data, the structural parameters were calculated. These are the carbon aromaticity $f_{a}$, the substitution degree of the aromatic systems $\sigma$, the atomic hydrogen to carbon ratio of the hypothetical unsubstituted aromatic material $\boldsymbol{I}_{u u} / \boldsymbol{C}_{u}$, and the average length of aliphatic carbon chain $\boldsymbol{H}_{0} / \boldsymbol{H}_{\alpha}$. The former three were already proposed by Brown and Ladner ${ }^{6}$, but the last one was a new parameter proposed by the present authors in their previous papers ${ }^{8,10)}$. The carbon numbers of aliphatic carbon chain $n$ can be calculated by the following equation: $n=1+\boldsymbol{H}_{0} / \boldsymbol{H}_{\alpha}$.

The extract of the youngest coal, peat, has a mono-ring system in its aromatic constitution and 8 carbon atoms as carbon numbers of the aliphatic side chain, and average numbers of condensed aromatic rings increased up to 6-7 with the increase of carbon content of parent coals, the largest one is the extract of Ohyubari coal which has the largest carbon content 85.6 per cent. But in regard to average numbers of carbon atoms in aliphatic systems, all coal extracts except for the two younger samples, Ishikari peat and Tokachi lignite, have almost the same carbon number $3-4$ in their aliphatic systems.

\section{Introduction}

Recently, high resolution nuclear magnetic resonance (NMR) spectroscopy has been adopted in the studies on the constitution of coal derivatives.

The first application of high resolution NMR spectroscopy to the studies of the constitution of coal-like materials was done on coal hydrogenation asphaltene by Friedel ${ }^{1)}$ in 1959 . Rao, Murty and Lahiri ${ }^{2)}$ investigated the hydrogen distribution of carbon disulphide solubles of coal tar pitch. Oth and Tschamler ${ }^{3,4}$ measured the NMR spectra of benzene extracts of coal in deuterobenzene solution. Friedel and Retcofsky ${ }^{5)}$ also reported on the structure of the deutero-pyridine extract of Pittsburgh coal by NMR spectroscopy.

Brown and Ladner ${ }^{6)}$ contributed especially to the development of structural analysis of coal-like materials with high resolution NMR measurement. They obtained the NMR spectra of vacuum distillates of coals and of the chloroformsoluble portion from the shock-carbonized coking coal in methylene chloride solution. They proposed three structural parameters for the analysis of the structure of coal-like materials by using quantitative hydrogen distribution among different types of hydrogen atoms in hydrocarbon groupings obtained from the NMR spectra of coal-like materials and the atomic ratios from their elementary analysis. 
One of the authors ${ }^{7)}$ previously measured the molecular weight of pyridine extracts of Japanese caking coals and investigated the distribution of the molecular weight in the pyridine extracts and chemical properties of the extracts in relation to coking properties of Japanese coals. The authors also reported briefly on the analytical and structural data of the pyridine extracts of some Japanese coals, based upon the hydrogen distribution from their NMR spectra and also upon their elementary analyses, in previous papers ${ }^{8,9,10)}$. The present report, including the previous experimental data and broadening the range of carbon contents of sample coals, deals again with the constitution of the pyridine extracts of twelve Japanese coals of different carbon contents covering peat, lignite, non-caking and caking bituminous coal.

\section{Experiments}

\section{Preparation of the pyridine extract of coal}

The twelve Japanese coals of different carbon contents were extracted with pure pyridine in Soxhlet apparatus for more than $24 \mathrm{hr}$. The solvent pyridine was distilled off from the extract solution under a reduced pressure of about $15 \mathrm{~mm} \mathrm{Hg}$ and the concentrated extract was finally subjected to steamdistillation. The pyridine extracts thus obtained were ground and dried over $\mathrm{P}_{2} \mathrm{O}_{5}$ under a reduced pressure of $1 \mathrm{~mm} \mathrm{Hg}$ at $70^{\circ} \mathrm{C}$ for $24 \mathrm{hr}$.

\section{Preparation of the sample for NMR measurement}

$67 \mathrm{mg}$. of each pyridine extract was placed in a thin-walled glass sample tube of $14 \mathrm{~cm}$ length and $0.5 \mathrm{~cm}$ outer diameter for NMR measurements. Deutero-pyridine, $\mathrm{C}_{5} \mathrm{D}_{5} \mathrm{~N},(0.6 \mathrm{cc})$, containing about 0.4 per cent tetramethyl silane (TMS) as an internal standard was added to the sample tube with a micro-injector. The concentration of the coal extract was approximately $10 \mathrm{wt}$. per cent of the solution in the sample tube. The sample tube was immediately sealed while cooling the bottom of the sample tube and then shaken sufficiently to dissolve the coal extract. The deutero-pyridine solutions of coal extracts thus prepared, were examined by high resolution NMR spectroscopy at $60 \mathrm{Mc}$. with a JNM-3H-60 NMR spectrometer.

\section{Result and discussion}

\section{Pyridine extracts}

The coal extracts obtained from the above described preparation have no pyridine odor, showing that pyridine used as solvent was evaporated almost completely. The analyses of parent coals and coal extracts are shown in Table 1 together with yields of extracts. The yield of extracts varied from 12 to 
TABLE 1. Analyses of coals and coal extracts (In weight percentage)

\begin{tabular}{|c|c|c|c|c|c|c|c|c|c|c|c|c|c|c|c|}
\hline \multirow{3}{*}{ Sample coals } & \multirow{2}{*}{\multicolumn{5}{|c|}{$\frac{\text { Coals (d.a.f.) }}{\text { Ultimate analysis }}$}} & \multicolumn{10}{|c|}{ Pyridine extracts (d.a.f.) } \\
\hline & & & & & & \multicolumn{4}{|c|}{ Ultimate analysis } & \multicolumn{5}{|c|}{$\begin{array}{l}\text { Oxygen distribution of various oxygen } \\
\text { containing groups }\end{array}$} & \multirow{2}{*}{ Yield } \\
\hline & $\mathrm{C}$ & $\mathrm{H}$ & $\mathrm{N}$ & $\mathrm{S}$ & (diff.) & $\mathrm{C}$ & $\mathrm{H}$ & $\mathrm{N}$ & $\begin{array}{c}\mathrm{O} \\
\text { (direct) }\end{array}$ & Оон & $\mathrm{O}_{\mathrm{c}}=\mathrm{o}$ & OоOOH & $\left|\begin{array}{c}\mathrm{O}_{\mathrm{C}-\mathrm{O}-\mathrm{c}} \\
\text { etc. }\end{array}\right|$ & $\frac{\mathrm{O}_{\mathrm{OH}}+\mathrm{O}_{\mathrm{C}=0}}{\mathrm{O}_{\text {tot }}}$ & \\
\hline Ishikari peat & 60.9 & 6.0 & 1.8 & 0.4 & 30.9 & 68.7 & 7.9 & 2.5 & 21.8 & 6.9 & 2.0 & 4.1 & 8.8 & 40.8 & 11.5 \\
\hline Tokachi lignite & 61.9 & 5.7 & 1.0 & 0.0 & 31.9 & 69.9 & 7.9 & 1.5 & 19.3 & 7.2 & 2.0 & 4.4 & 5.7 & 47.7 & 13.8 \\
\hline Sohya coal & 70.3 & 5.3 & 1.2 & 0.4 & 22.8 & 77.4 & 6.7 & 2.6 & $13.3^{*}$ & 6.8 & 1.7 & 0.6 & 4.2 & 63.9 & 16.6 \\
\hline Sumiyoshi coal & 75.5 & 6.1 & 1.2 & - & 17.1 & 78.4 & 6.8 & 1.6 & $13.2^{*}$ & 6.5 & 2.5 & 0.3 & 3.9 & 68.2 & 15.8 \\
\hline Taiheiyo coal & 76.7 & 6.4 & 0.7 & - & 16.2 & 80.6 & 7.4 & 1.3 & $10.7^{*}$ & 6.1 & 2.7 & 0.8 & 1.1 & 82.2 & 16.7 \\
\hline Shakubetsu coal & 77.6 & 5.8 & 1.9 & 0.6 & 14.1 & 76.2 & 6.3 & 2.9 & 13.6 & 5.7 & 2.6 & 0.8 & 4.5 & 61.0 & 12.8 \\
\hline Showa coal & 79.6 & 6.2 & 1.8 & 0.2 & 12.2 & 79.6 & 6.7 & 2.5 & 11.7 & 5.4 & 2.6 & 0.5 & 3.2 & 68.4 & 16.8 \\
\hline Shinhoronai coal & 80.1 & 6.5 & 1.6 & 0.1 & 11.2 & 80.3 & 6.8 & 2.4 & 11.4 & 4.6 & 2.0 & 0.7 & 4.1 & 57.9 & - \\
\hline Bibai coal & 80.7 & 6.0 & 1.7 & 0.1 & 11.4 & 80.0 & 6.1 & 2.5 & 11.2 & 5.4 & 2.2 & 0.4 & 3.2 & 67.9 & - \\
\hline Ohwada coal & 81.4 & 6.2 & 1.1 & 0.1 & 11.2 & 81.6 & 6.5 & 1.8 & 9.8 & 5.3 & 2.5 & 0.3 & 1.7 & 79.6 & 14.1 \\
\hline Yubari coal & 84.0 & 6.4 & 0.8 & - & 8.8 & 83.7 & 6.5 & 2.0 & $7.8^{*}$ & 2.3 & 1.4 & 0.0 & 4.1 & 47.4 & 18.5 \\
\hline Ohyubari coal & 85.6 & 6.6 & 1.5 & 0.2 & 6.0 & 84.5 & 6.4 & 2.0 & 6.7 & 2.6 & 2.1 & 1.0 & 1.0 & 70.1 & 20.0 \\
\hline
\end{tabular}

* Indicates that the oxygen estimation was done by subtracting $\mathrm{C}, \mathrm{H}$ and $\mathrm{N}$ from the total 100 
20 per cent of the parent coals. Contents of oxygen contained in various functional groups in the coal extracts which were determined by chemical methods ${ }^{19)}$ used on coal in our laboratory, are also shown in Table 1 . The infra-red spectra of coal extract $\mathrm{KBr}$ tablets showed that, although all the pyridine extracts from 12 coals showed a slight increase of absorption intensity on $\mathrm{C}-\mathrm{H}$ stretching vibration of aliphatic structure at $2920 \mathrm{~cm}^{-1}$ as compared with the parent coal $\mathrm{KBr}$ tablets, the spectra of the pyridine extracts were almost identical to those of the respective parent coals. As an example, the infra-red spectra of Sumiyoshi coal and its pyridine extract are shown in Fig. 1. Thus, it may be said that the pyridine extracts retain the characteristic features of the respective parent coals.

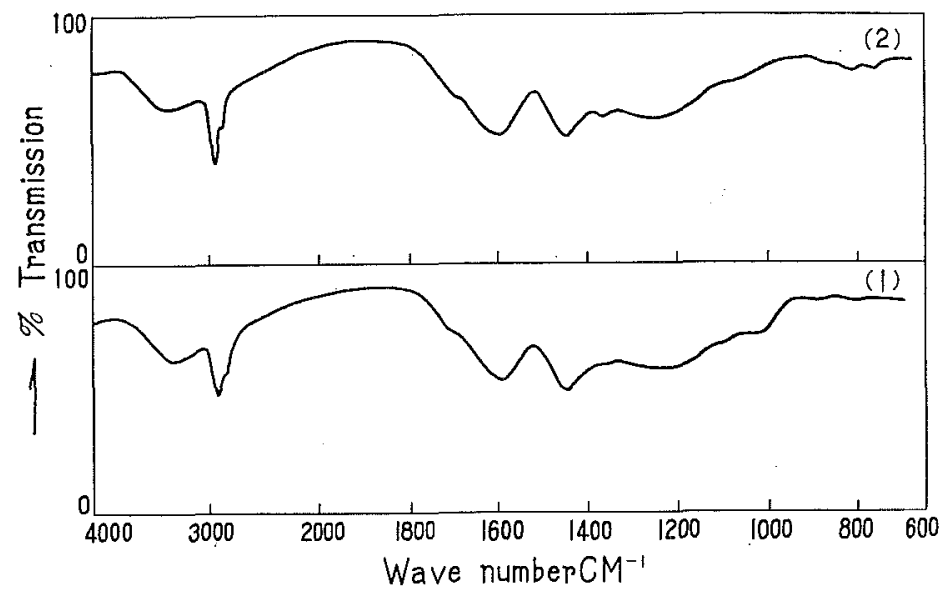

Fig. 1. Infra-red spectra of Sumiyoshi coal (1) and of its pyridine extract (2)

\section{NMR spectra of the coal extracts}

NMR spectra of the pyridine extracts of the 12 Japanese coals of different carbon contents are shown in Fig. 2. All signals of the different types of hydrogen atoms in hydrocarbon groupings for each extracts appeared respectively at identical positions and these intensities varied with the ranks of coals.

The broad peak located at the range of about $\delta=6.5$ to $\delta=9.0$ p.p.m. is assigned to aromatic hydrogen $\left(\boldsymbol{H}_{a}\right)$ in the coal extracts. However, it is noted that this peak includes the signals of hydrogen atoms (at $\alpha$-, $\beta$ - and $\gamma$-position) of pyridine $\mathrm{C}_{5} \mathrm{H}_{5} \mathrm{~N}$ which is the slight impurity contained in deuteropyridine (cf. Figs. 2 and 3). The signal assigned to hydrogen atom bonded to $\alpha$-carbon of the aliphatic side chain of the aromatic rings $\left(\boldsymbol{H}_{\alpha}\right)$ is located 


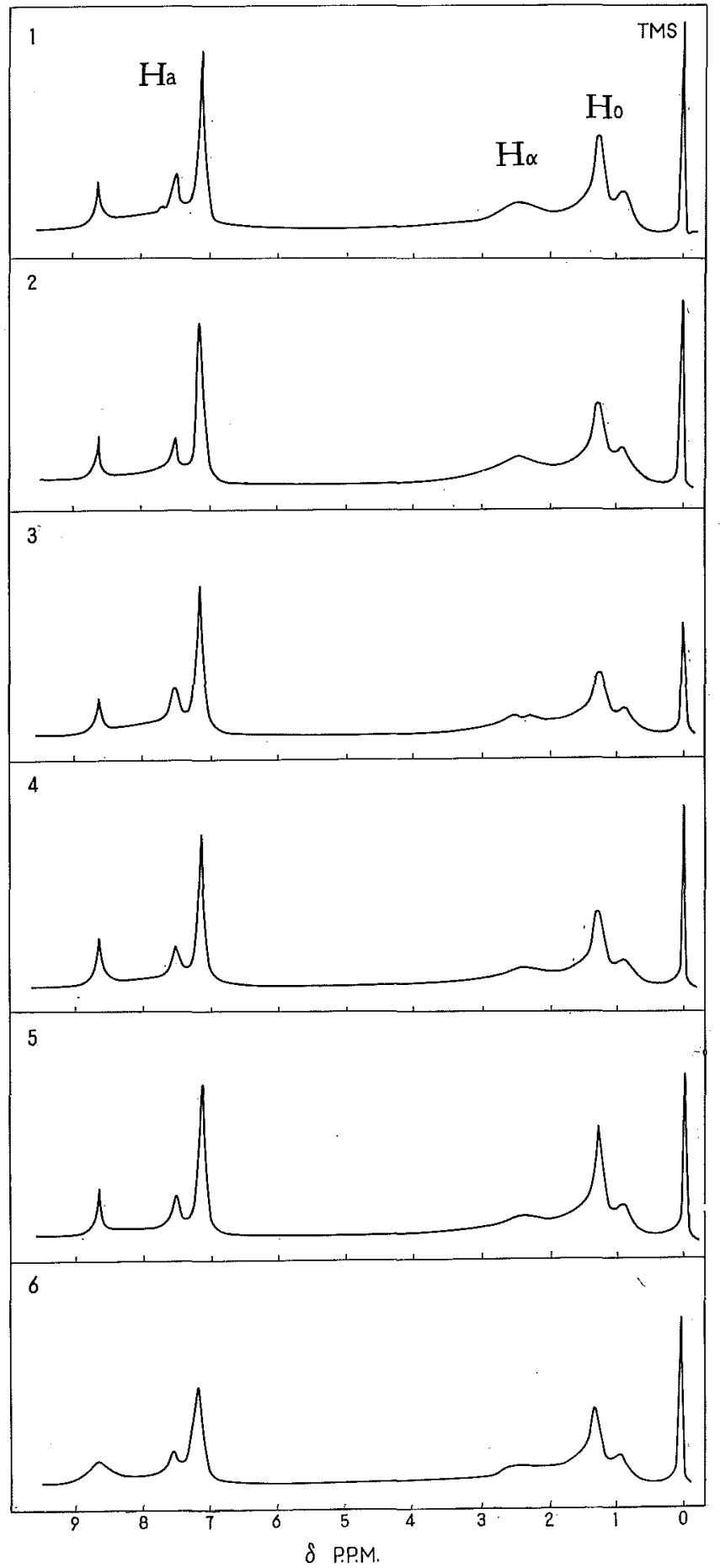

Fig. 2. NMR spectra of the pyridine extract in deutero-pyridine

1: Ohyubari coal 5: Shinhoronai coal

2: Yubari coal

3: Ohwada coal

4: Bibai coal
6: Showa coal

7: Shakubetsu coal

8: Taiheiyo coal
9: Sumiyoshi coal

10: Sohya coal

11: Tokachi lignite

12: Ishikari peat 


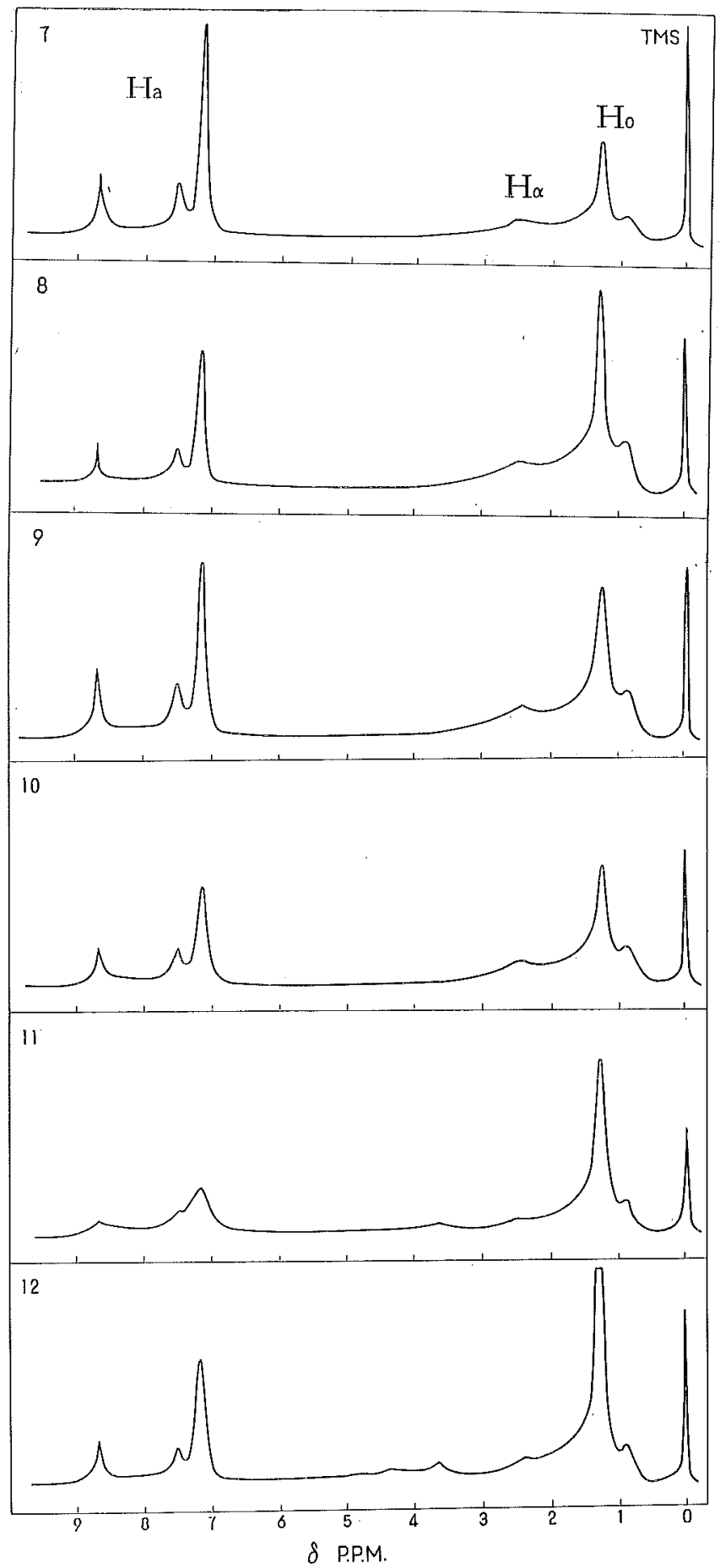


at near $\delta=2.5$ p.p.m.. Both independent signals situated at $\delta=1.28$ and $\delta=0.93$ p.p.m. are assigned to hydrogen atoms bonded to saturated carbon atoms except those of the $\alpha$-position to the aromatic rings $\left(\boldsymbol{H}_{0}\right)$. The signal appearing at $\delta=0.93$ p.p.m. may be assigned to methyl hydrogens except those bonded directly to aromatic rings.

NMR spectra of phenol and $\alpha$-naphtol in pyridine solution showed that signals of phenolic hydrogens are located at $\delta=11.43$ p.p.m. for phenol and $\delta=12.44$ p.p.m. for $\alpha$-naphtol ${ }^{10)}$. Also phenolic hydrogens of coal extracts in deutero-pyridine solution were expected to appear at a lower position of the applied magnetic field than $\delta=10$ p.p.m. But the resonance peak for phenolic hydrogen failed to appear in the NMR spectra even in the case of the Tokachi lignite extract which contained relatively high amounts of hydroxyl groups in its constitution. This may be attributed to the fact that the contents of hydroxyl groups in the extracts are relatively small $\left(H_{\mathrm{orI}} / H=0.057\right)$ and further, in the case of hydrogen-bonded compounds which are assumed to be contained in coal, the chemical shifts of phenolic hydroxyl protons vary over a wide spectral range in the lower magnetic field below $\delta=10$ p.p.m. by the effects of neighbouring groups. The peak intensity of aromatic hydrogen was estimated only on the signals of the higher magnetic field than $\delta=8.1$ p.p.m. as reported in a previous report ${ }^{8)}$. It is described in literature ${ }^{11,12}$ that the peaks of some proton in polynuclear aromatic hydrocarbons which have a deshielding, arising from the anisotropies of the $\pi$-electron system, appeared in fields lower than $\delta=8.1$ p.p.m. and the peak of the hydrogens bonded to carbon atoms adjacent to nitrogen or oxygen atoms in heterocyclic substances were observed also in fields lower than $\delta=7.4$ p.p.m. It may be clearly recognized that the polyaromatic compounds and heterocyclic structures containing oxygen and nitrogen are present in coal constitution ${ }^{13)}$. At the same time, since in the spectra of twelve pyridine extracts some signals appeared slightly in the lower field in the vicinity of $\delta=9.0$ p.p.m. $\sim \delta=8.1$ p.pm., the estimation of peak intensity of signals of aromatic hydrogen was extended to a new range of $\delta=6.5$ p.p.m. to $\delta=9.0$ p.p.m. in this paper.

Oth and Tschamler ${ }^{4)}$ observed a signal at $\delta=3.7$ p.p.m. on a fraction of benzene extarct of vitrinit ( $\mathrm{C}: 83.9 \%$ ) and assigned it to aliphatic hydrogen of the $\mathrm{CH}_{2}$-group between aromatic systems as in diphenylmethane types. Ishikari peat and Tokachi lignite also showed a small peak at $\delta=3.73$ p.p.m., while this peak failed to appear in the spectra of the extracts from bituminous coals. The NMR spectra of lignins in deutero-pyridine as well as in deuterodimethyl sulfoxide showed a remarkable peak assigned to methoxyl hydrogen at $\delta=3.7$ p.p.m. The signal at $\delta=3.73$ p.p.m. appearing in this study was 
observed only in two pyridine extracts obtained from low rank coals. Consequently, from the above described facts and also by the work of Tsukashima ${ }^{15)}$ on artificial coals, this signal was assigned to methoxyl hydrogen.

\section{Content ratio of hydrogen atoms of various types}

Content ratios of hydrogen atoms of various types in the structure of pyridine extracts were estimated by measuring the ratios of the areas under the respective NMR peaks to the total area of the spectrum. Since no signals of hydroxyl hydrogen were seen in the range of the magnetic field of $\delta=0 \sim$ $\delta=9.0$ p.p.m. on the deutero-pyridine solution, the hydrogen content corresponding to the total of the integrated area was revised by deduction of the hydroxyl hydrogen content obtained by chemical analysis from the value of the total hydrogen content by elementary analysis. To calculate the distribution of the hydrogen grouping, the hydrogen content deducted hydroxyl hydrogen-was distributed proportionally to each hydrogen grouping by the ratio of respective peak areas.

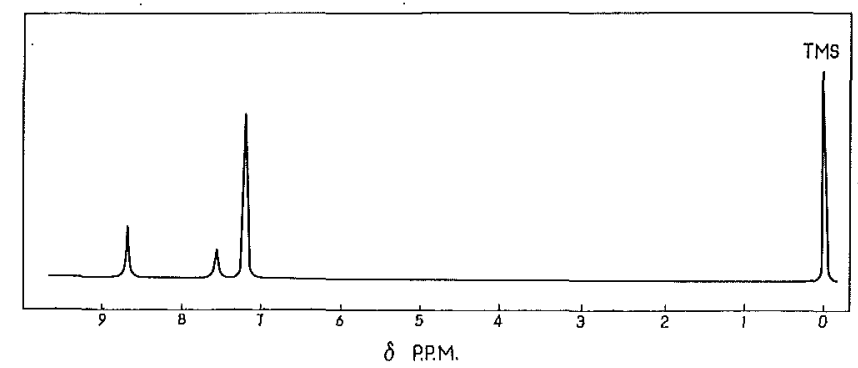

Fig. 3. NMR spectrum of deutero-pyridine used as the solvent

The NMR spectrum of deutero-pyridine used in this experiment was shown in Fig. 3. The signals of hydrogens at $\alpha$-, $\gamma$ - and $\beta$-position of pyridine, $\mathrm{C}_{5} \mathrm{H}_{5} \mathrm{~N}$, contained in deutero-pyridine as a slight impurity appeared at $\delta=8.7, \quad \delta=7.5$ and $\delta=7.2$ p.p.m. respectively. These signals of impurity appear overlapping with signals of aromatic hydrogens in the pyridine extract. Therefore, the integrated intensities of signals of aromatic hydrogens must be revised. In the NMR spectrum of the solvent containing a fixed quantity of tetramethyl silane, the integrated signal intensity of pyridine contained as an impurity was measured and compared with the intensity of the peak of tetramethyl silane, which was added to the solvent previously. Intensity of impurity signals which was calculated in proportion to the signal intensity of the internal standard contained in the sample solution, was deducted from that of the aromatic hydrogen band of the sample solution. Thus, the content of the aromatic hydrogen in the extracts were obtained. 
Content ratios of hydrogen atoms of various types $\left(H_{a}, H_{\alpha}, H_{0}\right.$ and $\left.H_{\mathrm{OH}}\right)$ to total hydrogen atoms $(H)$ were shown together with atomic $\operatorname{ratios}\left(\frac{\mathrm{C}}{\mathrm{H}}, \frac{\mathrm{O}}{\mathrm{H}}\right)$ in Table 2.

TABLE 2. Atomic ratio and hydrogen distribution of pyridine extracts

\begin{tabular}{|c|c|c|c|c|c|c|}
\hline \multirow[b]{2}{*}{ Parent coals } & \multicolumn{2}{|c|}{ Atomic ratio } & \multicolumn{4}{|c|}{ Hydrogen distribution } \\
\hline & $\frac{\mathrm{C}}{\mathrm{H}}$ & $\frac{\mathrm{O}}{\mathrm{H}}$ & $\frac{H_{\mathrm{OH}}}{\mathrm{H}}$ & $\frac{H_{a}}{\mathrm{H}}$ & $\frac{H_{\alpha}}{\mathrm{H}}$ & $\frac{H_{0}}{\mathrm{H}}$ \\
\hline Ishikari peat & 0.730 & 0.173 & 0.055 & 0.147 & 0.104 & 0.694 \\
\hline Tokachi lignite & 0.742 & 0.154 & 0.057 & 0.074 & 0.117 & 0.753 \\
\hline Sohya coal & 0.968 & 0.125 & 0.064 & 0.181 & 0.199 & 0.556 \\
\hline Sumiyoshi coal & 0.967 & 0.123 & 0.060 & 0.211 & 0.202 & 0.527 \\
\hline Taiheiyo coal & 0.914 & 0.091 & 0.053 & 0.096 & 0.208 & 0.643 \\
\hline Shakubetsu coal & 1.014 & 0.136 & 0.058 & 0.324 & 0.209 & 0.409 \\
\hline Showa coal & 0.997 & 0.110 & 0.051 & 0.204 & 0.244 & 0.501 \\
\hline Shinhoronai coal & 0.991 & 0.105 & 0.042 & 0.220 & 0.216 & 0.522 \\
\hline Bibai coal & 1.101 & 0.116 & 0.056 & 0.274 & 0.220 & 0.450 \\
\hline Ohwada coal & 1.053 & 0.095 & 0.051 & 0.356 & 0.207 & 0.383 \\
\hline Yubari coal & 1.081 & 0.076 & 0.022 & 0.296 & 0.257 & 0.429 \\
\hline Ohyubari coal & 1.109 & 0.066 & 0.027 & 0.285 & 0.237 & 0.450 \\
\hline
\end{tabular}

$H_{a}, H_{\alpha}, H_{0}$ and $H_{\mathrm{OII}}$ respectively represent the content of aromatic hydrogen atoms, the content of hydrogen atoms bonded to carbons of $\alpha$-position to the aromatic rings and bonded to other saturated carbon atoms and also the content of hydrogen contained in hydroxyl groups. The content ratio of hydroxyl hydrogen to total hydrogen, $\frac{H_{\mathrm{OH}}}{\mathrm{H}}$, decreased from 0.064 to 0.022 with the increase of degree of coalification of parent coals. The content ratios of aromatic hydrogen, $\frac{H_{a}}{\mathrm{H}}$, increased from 0.074 to 0.356 and those of aliphatic hydrogen except for hydrogen bonded to $\alpha$-position carbon to aromatic ring, $\frac{H_{0}}{\mathrm{H}}$, decreased from 0.753 to 0.383 . But in the case of hydrogen atoms bonded to $\alpha$-position carbon to aromatic ring, $\frac{H_{\alpha}}{\mathrm{H}}$, their content ratios show nearly constant values of 0.20 to 0.26 except for the extracts of peat and Tokachi lignite, which showed values of about 0.10 and 0.12 respectively. It seems to show that the degree of aromaticity increases and the condensing 
of aromatic rings in the structure of pyridine extracts progress gradually with the advance of coalification.

\section{Structural parameter}

In the studies of the structure of coal derivatives Brown and Ladner ${ }^{6}$ ) introduced three structural parameters based upon the contents of the different types of hydrogen atoms obtained from the NMR spectrum and data on the elementary analysis. These three structural parameters are $f_{a}$ (carbon aromaticity), $\sigma$ (the degree of the substitution of the aromatic system) and $\boldsymbol{H}_{a u} / \boldsymbol{C}_{1}$ (the atomic hydrogen to carbon ratio of the hypothetical unsubstituted aromatic material). The authors proposed another structural parameter $\boldsymbol{H}_{0} / \boldsymbol{H}_{\alpha}$ (average length of aliphatic carbon chains) for the analysis of the structure of pyridine extracts from Japanese coals in the previous papers ${ }^{8,10}$.

The degree of average length of aliphatic carbon chains attached to the aromatic system is estimated on the basis of the following relation:

$$
\frac{\boldsymbol{H}_{0}}{\boldsymbol{H}_{\alpha}}=\frac{H_{0}}{H} \cdot \frac{1}{y} / \frac{H_{u}}{H} \cdot \frac{1}{x} .
$$

In this equation, the values for $x$ and $y$ are respectively the atomic ratios of hydrogen to carbon in the $\alpha$-position to aromatic rings and that in the aliphatic side chain except for the $\alpha$-position: $x=H_{\alpha} / C_{\alpha}, y=H_{0} / C_{0} . \quad$ And average numbers of carbon atoms, $n$, in aliphatic carbon chains to aromatic rings is given as follows:

$$
n=1+\boldsymbol{H}_{0} / \boldsymbol{H}_{\alpha} .
$$

In this paper the four structural parameters above clescribed were adopted for the analysis of constitution of the twelve pyridine extracts. Furthermore in regard to the value of $\sigma$, an attempt was made to divide the $\sigma$ value into the two following values, $\sigma_{a l}$ (substitution by aliphatic groups) and $\sigma_{0}$ (substitution by oxygen containing groups), and these values were shown in Table 3.

The following items have been assumed for the derivation and use of the above four parameters on the structure of pyridine extracts.

1) Contents of nitrogen and sulphur as constitutive elements may be negligible. 2) Almost all oxygen atoms are directly bonded to the aromatic systems, that is to say, practically most of all oxygens occur as phenolic hydroxyl and quinone groups and are not linked between aromatic systems as in diphenylether and diphenylen-oxide. 3) The aromatic rings are linked neither directly with each other nor by one methylene bridge, as in the structure of diphenyl and diphenylmethane. 4) 2 is adopted for the values of $x$ and $y$ as an approximation. Furthermore, the following two assumptions are added for the 
use of the parameter for the length of aliphatic carbon chains, $\frac{\boldsymbol{M}_{0}}{\boldsymbol{H}_{\alpha}}$, on the structure of pyridine extracts. 5) The main portion of aliphatic systems are saturated and bonded to the aromatic systems. 6) As regards to the oxygen groups, the structure of phenylalkyl ether types does not occur.

Assumption ( 1 ) is accepted generally from the elemental analysis. As for assumption (2), the fraction of hydroxyl and carbonyl oxygen to total oxygens is more than 60 per cent on the pyridine extracts except for the values of 41 per cent on Ishikari peat extract, 47 per cent on Tokachi extract and Yubari extract as shown in Table 1. The non-reactive oxygen contents were small in the coal extracts, hence aromatic ether types may be ignored. As for assumption (3), the resonance peak near $\delta=3.9$ p.p.m. assigned to methylene hydrogens of diphenylmethane structure did not appear in the spectra of pyridine extracts. Structural information of diphenyl types in assumption (3) is insufficient for the pyridine extracts at present. But the absence of diphenyl types may be explained by the consideration as proposed by Brown and Ladner ${ }^{6)}$. Assumption (4), Brown and Ladner ${ }^{6)}$ adopted 2 for the values of $x$ and $y$ on low-temperature vacuum carbonization products. Tschamler and Ruiter ${ }^{17)}$ introduced the following parameter: $\left(H_{\alpha}+H H_{0}\right) /\left(C_{\alpha}+C_{0}\right)$ $=\left(H_{a z} / C_{a l}\right)=z$, and reported the value of $z$ from 1.9 to 2.2 on coal structure on the basis of broad-line NMR measurement. Assumption (5), paraffinic substances in the extracts have been stated to exist in minor amounts by Halleux ${ }^{16)}$. Assumption (6), on the NMR spectra of standard substances of phenylalkyl ether structure, the signal of hydrogen atoms bonded to carbon atoms of $\alpha$-position with respect to oxygen appears at fields lower than $\delta=3.0$ p.p.m. But all spectra of the extracts except for the extracts of Tokachi lignite and of peat failed to show such signals. In the case of Tokachi lignite and peat, a signal appeared at $\delta=3.7$ p.p.m. as above described.

\section{Values of the structural parameters for the pyridine extracts}

Values calculated for the structural parameters; $f_{a}, \boldsymbol{H}_{a u} / \boldsymbol{C}_{a}, \sigma$ and $\boldsymbol{H}_{0} / \boldsymbol{H}_{\alpha}$ are shown in Table 3. Fig. 4 gives a plot of the values of $f_{a}, \boldsymbol{H}_{a u} / \boldsymbol{C}_{a}, \sigma$ and $\boldsymbol{H}_{0} / \boldsymbol{H}_{\alpha}$ against the carbon content of the parent coals. The values for aromaticity, $f_{u}$, in the pyridine extracts increased from 0.41 to 0.72 with the increase of the carbon content in the parent coals. The values found for $\boldsymbol{H}_{n u} / \boldsymbol{C}_{u}$ indicate a decreasing tendency from 1.12 to 0.60 . These showed the increasing tendency of the numbers of condensed rings with the increase of the carbon content in the parent coals. The values found for the degree of ring substitution indicate a decrease from 0.74 to 0.36 with the increase of the carbon content in the parent coals. This tendency was also seen in the infra-red 
TABLE 3. Structural parameters and mean structure of pyridine extracts

\begin{tabular}{|c|c|c|c|c|c|c|c|c|c|}
\hline \multirow{3}{*}{ Parent coals } & \multicolumn{6}{|c|}{ Structural parameters of pyridine extracts } & \multicolumn{3}{|c|}{ Mean structure of pyridine extracts } \\
\hline & \multirow{2}{*}{$f_{a}$} & \multirow{2}{*}{$\boldsymbol{H}_{a u} / \boldsymbol{C}_{a}$} & \multirow{2}{*}{$\sigma$} & \multirow{2}{*}{$\sigma_{a l^{*}}$} & \multirow{2}{*}{$\sigma_{0}^{*}$} & \multirow{2}{*}{$\frac{\boldsymbol{H}_{0}}{\boldsymbol{H}_{\alpha}}$} & \multicolumn{2}{|c|}{$\begin{array}{l}\text { Number of condensed } \\
\text { aromatic rings }\end{array}$} & \multirow{2}{*}{$\begin{array}{l}\text { Number of } \\
\mathrm{C} \text { atoms in } \\
\text { aliphatic } \\
\text { C-chain** }\end{array}$} \\
\hline & & & & & & & $\begin{array}{l}\text { If cata-con- } \\
\text { densed type }\end{array}$ & $\begin{array}{l}\text { If peri-con- } \\
\text { densed type }\end{array}$ & \\
\hline Ishikari peat & 0.45 & 1.12 & 0.61 & 0.14 & 0.47 & 6.7 & 1 & & 8 \\
\hline Tokachi lignite & 0.41 & 0.93 & 0.74 & 0.20 & 0.54 & 6.4 & $1-2$ & & $7-8$ \\
\hline Sohya coal & 0.61 & 0.69 & 0.55 & 0.25 & 0.30 & 2.8 & $3-4$ & & 4 \\
\hline Sumiyoshi coal & 0.62 & 0.72 & 0.52 & 0.23 & 0.29 & 2.6 & 3 & & $3-4$ \\
\hline Taiheiyo coal & 0.53 & 0.60 & 0.67 & 0.36 & 0.31 & 3.1 & 7 & 5 & 4 \\
\hline Shakubetsu coal & 0.70 & 0.80 & 0.43 & 0.19 & 0.24 & 2.0 & 2 & & 3 \\
\hline Showa coal & 0.63 & 0.70 & 0.53 & 0.28 & 0.25 & 2.1 & $3-4$ & & 3 \\
\hline Shinhoronai coal & 0.63 & 0.70 & 0.49 & 0.25 & 0.24 & 2.4 & $3-4$ & & $3-4$ \\
\hline Bibai coal & 0.70 & 0.65 & 0.45 & 0.22 & 0.23 & 2.0 & $4-5$ & & 3 \\
\hline Ohwada coal & 0.72 & 0.74 & 0.36 & 0.19 & 0.17 & 1.9 & $2-3$ & & 3 \\
\hline Yubari coal & 0.69 & 0.67 & 0.41 & 0.25 & 0.16 & 1.7 & 4 & & 3 \\
\hline Ohyubari coal & 0.69 & 0.61 & 0.39 & 0.25 & 0.14 & 1.9 & $6-7$ & $4-5$ & 3 \\
\hline
\end{tabular}

* $\sigma_{a l}$ : Aliphatic substitution; $\sigma_{0}$ : Substitution by oxygen containing groups

** Number of $\mathrm{C}$ atoms $\doteqdot\left(\boldsymbol{H}_{0} / \boldsymbol{H}_{\alpha}\right)+1$ 
analysis of the pyridine extracts concerning the intensity of characteristic absorption bands from $900 \mathrm{~cm}^{-1}$ to $600 \mathrm{~cm}^{-1}$ which indicate the degree of the substitution of aromatic systems. Values of the structural parameter $\boldsymbol{H}_{0} / \boldsymbol{H}_{\alpha}$ vary from 6.7 to 1.7 . These results indicated the decrease of the average length of the aliphatic chains with the increase of the carbon content in the parent coals.

The content of the constitution elements and atomic ratios $(\mathrm{H} / \mathrm{C}$ and $\mathrm{O} / \mathrm{C})$ of the pyridine extracts differed from those of the parent coals, and the difference among the extracts was rather less than in the coals, as reported in our previous paper ${ }^{7}$. But in the present NMR studies, all of the values of the structural parameters of pyridine extracts obtained from different ranks of coal varied with the degree of coalification.

\section{Mean structure of pyridine extracts}

The values for $\boldsymbol{M}_{u u} / \boldsymbol{C}_{\boldsymbol{t}}$ calculated from various unsubstituted polynuclear aromatic substances are shown in Table 4 for the convenience of understanding the mean structures of 12 pyridine extracts. The

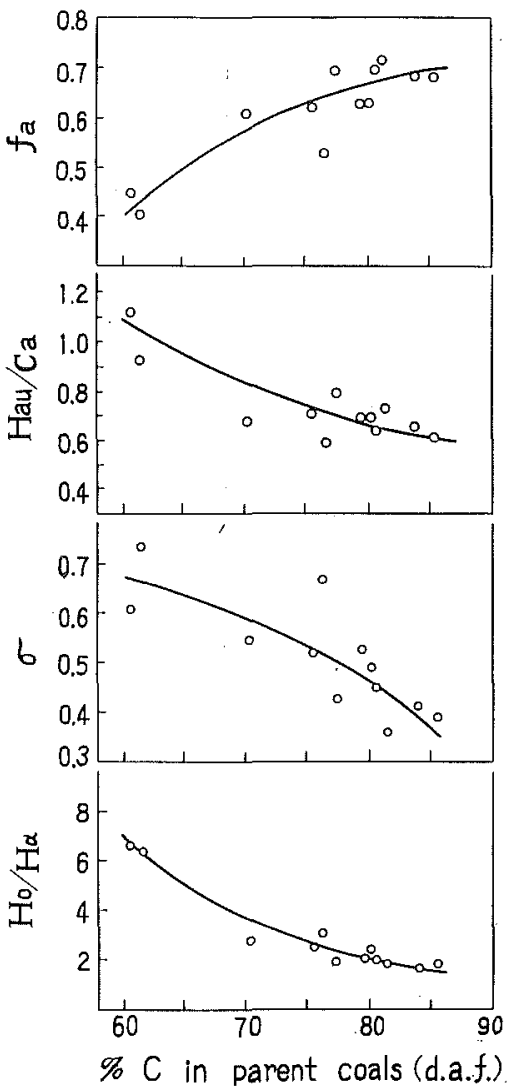

Fig. 4. A plot of $f_{a}, \boldsymbol{H}_{a u} / \boldsymbol{C}_{a}, \sigma$ and $\boldsymbol{\Pi}_{0} / \boldsymbol{H}_{\alpha}$ for the pyridine extracts of coals against the carbon content of the parent coals

number of condensed aromatic rings shown in Table 3 , were estimated by comparing the values calculated for $\boldsymbol{H}_{a u} / \boldsymbol{C}_{a}$ of the samples with the values of the standard shown in Table 4, and these values varied from 1 to 6 or 7 rings with the increase of carbon content in the parent coals. The number of aromatic rings in Table 3 indicated 1 or 2 less values than the results reported in the previous paper ${ }^{8,9)}$. In the present study, the resonance peak intensities of aromatic hydrogen were integrated over a range of $\delta=6.5$ p.p.m. to $\delta=9.0$ p.p.m., but in our previous papers ${ }^{8,9)}$ the range was from $\delta=6.5$ to $\delta=8.1$ p.p.m.

The average numbers of carbon atoms in the aliphatic carbon chains bonded to aromatic systems were shown in Table 3. All extracts, with the 
TABLE 4. $\quad \boldsymbol{H}_{n u} / \boldsymbol{C}_{n}$ of various aromatic substances

\begin{tabular}{|c|c|c|c|c|}
\hline $\begin{array}{c}\text { Aromatic } \\
\text { Substances }\end{array}$ & $\mathrm{Ca}$ & $\mathrm{Hau}$ & $R_{n}$ & $\frac{\mathrm{Hay} / \mathrm{Ca}}{\mathrm{Ca}}$ \\
\hline & 6 & 6 & 1 & 1.00 \\
\hline & 10 & 8 & 2 & 0.80 \\
\hline & 14 & 10 & 3 & 0.71 \\
\hline & 14 & 10 & 3 & 0.71 \\
\hline & 18 & 12 & 4 & 0.67 \\
\hline & 18 & 12 & 4 & 0.67 \\
\hline & 22 & 14 & 5 & 0.64 \\
\hline & 22 & 14 & 5 & 0.64 \\
\hline & 16 & 10 & 4 & 0.62 \\
\hline & 26 & 16 & 6 & 0.62 \\
\hline & 20 & 12 & 5 & 0.60 \\
\hline & 20 & 12 & 5 & 0.60 \\
\hline & 30 & 18 & 7 & 0.60 \\
\hline & 22 & 12 & 6 & 0.55 \\
\hline & 24 & 12 & 7 & 0.50 \\
\hline & 30 & 14 & 9 & 0.47 \\
\hline
\end{tabular}

$R_{n}:$ Number of aromatic rings

exception of the two younger samples, had almost the same carbon number, 3-4, in these aliphatic systems, but Ishikari peat and Tokachi lignite had 8 and $7-8$ carbon atoms respectively in these aliphatic systems. The values for degree of aromatic substitution $\sigma$ and its breakup values, $\sigma_{a l}$ and $\sigma_{0}$, were also shown in Table 3.

\section{Acknowledgment}

The authors are grateful for the help given by Mr. S. Shimokawa of the Faculty of Engineering, Hokkaido University for the measurement of NMR spectra. 


\section{References}

1) R. A. Friedel : J. Chem. Phys., 31, 280 (1959).

2) H. S. Rao, G. S. Murty and A. Lahiri: Fuel, 39, 263 (1960).

3) J. F. M. Oth and H. Tschamler: Fuel, 40, 119 (1961).

4) J. F. M. Oth and H. Tschamler: Brennstoff-Chemie, 43, 177 (1962).

5) R. A. Friedel and H. Retcofsky: Proceedings of the Fifth Carbon Conference, II, 149 (1963).

6) J. K. Brown, W. R. Ladner and N. Sheppard: Fuel, 39, 79 (1960).

J. K. Brown and W. R. Ladner: Ibid., 39, 87 (1960).

7) G. Takeya, M. Kugo, K. Makino and M. Makabe: Kogyo Kagaku Zasshi, 61, 206 (1958).

8) G. Takeya, M. Itoh, A. Suzuki and S. Yokoyama: Bull. Chem. Soc. Japan, 36, 1222 (1963).

$9)$ G. Takeya, M. Itoh, A. Suzuki and S. Yokoyama: Bulletin of the Faculty of Engineering, Hokkaido University, No. 35, 129 (1964).

10) G. Takeya, M. Itoh, A. Suzuki and S. Yokoyama: J. Fuel Soc. Japan, 43, 834 (1964).

11) H. J. Bernstein and W. G. Schneider: J. Chem. Phys., 24, 468 (1956).

$12)$ L. M. Jackman: Nuclear Magnetic Resonance Spectroscopy, (1959) Pergamon Press.

13 ) D. W. van Krevelen and J. Schuyer: Coal Science, 216 (1957), Elsevier.

14) G. Takeya, T. Ishii, S. Yokoyama and T. Okamoto: The 18th Annual Meeting of the Chemical Society of Japan, Osaka, April, 1965.

15) H. Tsukasima, S. Yokoyama, M. Itoh and G. Takeya: Bulletin of the Faculty of Engineering, Toyama University, 16, 39 (1965).

16) A. Halleux and H. de Greef: Fuel, 42, 185 (1963).

17) H. Tschamler and E. de Ruiter: Brennstoff-Chemie, 44, 48 (1963).

18) G. Takeya, M. Itoh, K. Makino and S. Yokoyama: Bulletin of the Faculty of Engineering, Hokkaido University, No. 35, 113 (1964). 